\title{
A PERCEPÇÃO DO PROFISSIONAL DE ENFERMAGEM AO CUIDAR DE CRIANÇAS SUBMETIDAS A TRANSPLANTE DE CÉLULAS TRONCO HEMATOPOÉTICAS - ESTUDO FENOMENOLÓGICO.
}

\author{
Nursing professionals' perception upon the caretaking of children submitted to bone marrow \\ transplantation - A Phenomenological Study.
}

Ingrid Meireles Gomes', Alzira Maria Stelmatchuk², Leomar Albini², Eloise Cristina Magajevski Sanches³, Liza Regina da Veiga Bueno³.

\begin{abstract}
RESUMO
Procedimentos de alta complexidade como o transplante de medula óssea, geram sentimentos de incerteza, medo, aflição principalmente quando relacionados à pediatria, que é um tema que preocupa e ao mesmo tempo encanta. Objetivo: compreender como profissionais de enfermagem se percebem ao prestar assistência a crianças submetidas a transplante de medula óssea. Método: análise de discurso com abordagem fenomenológica. Resultados: apontaram para dois temas principais relacionados ao cuidado de enfermagem à criança submetida a transplante de células-tronco hematopoéticas: a exigência de constante enfrentamento de desafios e dificuldades, refletido na necessidade de educação permanente, e o envolvimento emocional, espiritualidade, a condição de maternidade e a família como influências presentes. Conclusão: falta de preparo do profissional em lidar com peculiaridades da pediatria embutidas no processo de transplante e o esmero dos profissionais nesse tipo de serviço.
\end{abstract}

Descritores: Criança Hospitalizada; Transplante de Medula Óssea; Enfermagem; Carga de Trabalho.

\footnotetext{
Instituições:

${ }^{1}$ Núcleo de Estudos, Pesquisa e Extensão em Cuidado Humano de Enfermagem. Departamento de Enfermagem da Universidade Federal do Paraná, Curitiba, PR, Brasil;

${ }^{2}$ Coordenação de Enfermagem do Hospital de Clínicas da Universidade Federal do Paraná, Curitiba, PR, Brasil;

${ }^{3}$ Departamento de Enfermagem da Prefeitura Municipal de Curitiba, PR, Brasil.
}

Correspondência:

Ingrid Meireles Gomes

Rua Padre Camargo, 280 - $8^{\circ}$ andar. Alto da Glória. Curitiba - Paraná. CEP: 80060-240.

Telefone: (41) 3360-7261

E-mail: inguide@gmail.com

Recebido em: 28.12.2009

Aceito em: 15.01 .2010

\section{INTRODUÇÃO}

A criança ao nascer se depara com um determinado ambiente sociocultural com características específicas, que será a partir de então seu mundo. Espera-se um desenvolvimento saudável, marcado pelas peculiaridades de cada fase natural de desenvolvimento da vida. Entretanto, em determinadas ocasiões, não se tem um percurso tão natural do desenvolvimento, como ocorre em situações de adoecimento e hospitalização da criança. A modificação do estado usual de saúde e da rotina ambiental em crianças é mais acentuada, porque elas possuem um número limitado de mecanismos de enfrentamento para resolver seus estressores.

O evento de internamento para tratamento de doenças graves é marcado pelo aumento do estresse, principalmente ante a possibilidade da perda ou de sequelas irreversíveis, como no caso da necessidade do transplante de células-tronco hematopoéticas. Para a criança, esse evento representa o rompimento de suas atividades cotidianas, com limitações quanto à socialização, hábitos preexistentes, habilidades e ao brincar. ${ }^{1}$

Assim como para as famílias e para a própria criança a hospitalização é uma situação de estresse e angústia, também o é para a equipe de enfermagem, especialmente se essa equipe não tem preparo adequado, não recebeu treinamento específico para o atendimento de crianças e familiares e não entende a diferença existente no cuidado às crianças e aos adultos. 
Há marcas históricas da construção do significado de cuidar de crianças, tanto na Medicina, como a edificação do primeiro hospital infantil em 1802 e as realizações do médico Abraham Jacobi, considerado o pai da Pediatria, ${ }^{2}$ quanto na enfermagem, já com Florence Nightingale, que lançou os fundamentos da enfermagem pediátrica. $^{3}$ Assim, passou-se a perceber a responsabilidade dos profissionais de enfermagem, que ao assumir os cuidados a uma criança, responsabilizam-se também pelos pais ou acompanhante dela e as implicações que isso pode trazer; precisam ensinar, orientar, supervisionar, auxiliar, apoiar, e certificar-se de que tudo transcorra da melhor forma possível.

Em se tratando de procedimentos de alta complexidade, como é o caso do transplante de células tronco hematopoéticas, todas essas questões relacionadas a pacientes, famílias e equipe estão bastante presentes. No caso de crianças submetidas a tal situação, a importância desse fato é ainda muito maior. A equipe de enfermagem é parte significativa do processo, e, talvez, a maior responsável pelo sucesso do transplante. O transplante de células-tronco hematopoéticas representa uma área em que o conhecimento clínico encontra-se em expansão nos últimos 20 anos, devido à sua eficácia em salvar vidas, ${ }^{4}$ o que gera grande preocupação com o atendimento de todas as necessidades para a pronta recuperação do paciente.

Assim sendo, na hospitalização de uma criança faz-se necessário que os profissionais de enfermagem preocupem-se com a observação detalhada dessa criança atentando para suas manifestações emocionais e procurem estabelecer uma relação de confiança com ela, por meio de um planejamento adequado para cada caso, visando a adaptação e ajuste da criança ao novo ambiente. Isso porque, ao estabelecer uma relação de confiança com o paciente e com a família, os profissionais de enfermagem viabilizam avanços no tratamento, na resposta terapêutica e até mesmo no tempo de internação.

Nem sempre os profissionais de enfermagem estão preparados para lidar com situações de risco; muito de sua própria personalidade, suas crenças, sua maneira de ser, pensar e agir aflora diante de questões nem sempre muito claras, como por exemplo, crianças recém-nascidas e a fragilidade atribuída a elas, quando estão no limite entre a vida e a morte, sem nem mesmo terem começado a viver de fato. Tudo isso é causa constante de grande frustração e desconsolo para a equipe.

Diante de questões tão delicadas à natureza humana, não se deve esquecer que aqueles que cuidam, devem também estar sujeitos ao cuidado, visto que se relacionam com vinculação de seu lado pessoal, seja um cuidador profissional ou não, gerando desgaste do seu self. ${ }^{5}$

Nos cuidados especificamente relacionados com crianças submetidas a transplante de células tronco hematopoéticas, os profissionais de enfermagem estão muito mais vulneráveis a situações de estresse, porque o tempo de internação é bastante longo, devido ao tratamento com altas doses de quimioterapia, uso de antibióticos e risco de complicações, porque os pais e/ou acompanhantes demandam tempo maior para se adequarem à nova situação e conseguirem colaborar; além de nem sempre existir um prognóstico favorável, pois as complicações decorrentes do procedimento podem ser bastante graves e levar a criança a óbito.
Essa relação profissional X paciente/família, mais significativamente quando se trata de crianças, destaca-se em serviços de alta complexidade, como o de transplante de medula óssea ou de células tronco hematopoéticas. Dessa forma, este estudo teve como objetivo compreender como os profissionais de enfermagem percebem o prestar assistência a crianças submetidas a transplante de células tronco hematopoéticas.

\section{MÉTODOS}

Trata-se de um estudo original, realizado em um hospital público de ensino, de grande porte, centro de referência para diversas especialidades, destacando-se o serviço de transplante de células tronco hematopoéticas, designado no hospital em estudo como Serviço de Transplante de Medula Óssea (STMO), composto por 16 leitos de internação, destinado a crianças e adultos indistintamente. Pioneiro na América Latina, já realizou mais de 1500 transplantes desde 1979; atualmente, encontra-se entre os principais centros mundiais capazes de realizar esse tipo de procedimento.

O projeto foi aprovado pelo Comitê de Ética e Pesquisa da Instituição CEP/HC, sob o protocolo no 1045.083/2005-06, CAAE 0076.0.208.000-05, considerando-se o previsto na resolução no 196/96 do Conselho Nacional de Saúde ${ }^{6}$ sobre pesquisa envolvendo seres humanos. ${ }^{6}$ As entrevistas aconteceram após leitura, aprovação e assinatura do Termo de Consentimento Livre e Esclarecido, sendo respeitado o anonimato e o direito de desistência sem ônus pessoal.

Foram incluídos no referido estudo, por opção dos pesquisadores, os profissionais da equipe de enfermagem que atuam no STMO e prestam assistência direta e integral ao paciente, vivenciando o cuidado diário; sejam eles técnicos de enfermagem ou enfermeiros nos turnos da manhã, tarde e noite, independente de sexo ou raça. Os dados foram coletados até sua saturação, o que compreendeu um total de oito profissionais.

As entrevistas foram gravadas e posteriormente transcritas; a seguir, ocorreu sua devolução, para que os profissionais analisassem suas falas e fizessem as devidas modificações, caso achassem necessário; sendo que, apenas um dos entrevistados alterou o conteúdo de sua entrevista.

A análise dos discursos foi realizada segundo a trajetória fenomenológica proposta por Martins e Bicudo, ${ }^{7}$ que consiste de três momentos: descrição, redução e compreensão fenomenológica.

A descrição compreende o registro da comunicação do sujeito, na forma mais pura de captar sua essência. É preciso identificar o fenômeno que está sendo descrito, sem que se imponha algo sobre ele e sem concluir nada sobre ele apressadamente. ${ }^{5}$ É preciso ver o dado de maneira aberta e desvelar os significados da experiência vivida. A redução deve ser livre de pré-conceitos e pré-supostos pessoais ou de qualquer teoria que pretenda explicar o fenômeno. ${ }^{7}$ A compreensão busca desvelar o significado do que é essencial tanto na descrição quanto na redução para que, por meio das unidades de significado, chegue-se à consciência do fenômeno, por meio da experiência vivida.? 


\section{RESULTADOS}

A partir dos dados obtidos e seguindo o caminho metodológico supracitado, emergiram dois temas relacionados ao cuidado de enfermagem à criança submetida à transplante de células tronco hematopoéticas: "a exigência de constante enfrentamento de desafios e dificuldades, refletido na necessidade de educação permanente"; e "o envolvimento emocional, a espiritualidade, a condição de maternidade e a família como influências presentes".

\section{A exigência de constante enfrentamento de desafios e dificuldades, refletido na necessidade de educação permanente.}

Dentre os aspectos identificados nesse primeiro tema, o que mais se destaca no discurso dos profissionais e o sentimento de despreparo para atuar na situação específica de uma criança transplantada.

“(...) atividade bastante dificil; foi uma coisa imposta pra gente, não tivemos muita escolha..., pra mim é um desafio, em primeiro lugar..."(II)

“(...) eu não me sinto capacitada pra isso porque eu não fui treinada pra cuidar de criança.” (I)

Há dificuldade pela falta de preparo técnico, falta de conhecimento científico, receio de envolver-se e sofrer demasiadamente com o que não pode ser evitado. Há também dificuldades frente à comunicação com crianças que, em geral, não entendem o motivo de sua internação prolongada, as limitações impostas pelo tratamento, necessidade de medicações tão variadas e procedimentos por vezes bastante dolorosos.

Além disso, a presença dos pais e/ou acompanhantes ininterruptamente parece, muitas vezes, causar certo desconforto aos profissionais, que também manifestam dificuldade em interagir e incentivar a participação da família no cuidado diário prestado à criança.

A consciência e o desejo de aperfeiçoamento estão muito presentes nos profissionais que fazem parte da equipe de enfermagem do Serviço:

“(...) o transplante pra eles representa geralmente uma vida nova... o envolvimento da gente nisso é importante...” (I)

“(...) eu preciso estudar mais, preciso me aperfeiçoar, preciso estudar mais pra poder cuidar melhor dessas crianças..." (II)

Os próprios profissionais reclamam a necessidade de apoio e orientação, a fim de melhorar suas habilidades técnicas e alcançar equilíbrio emocional, como pode ser constatado nas seguintes declarações:

\section{“(...) a educação continuada dentro do setor poderia se voltar mais pra esse lado, frisar um pouco mais a questão da pediatria..." (IV) \\ “(...) deveríamos ter um preparo psicológico pra estar abordando essa criança, trabalhar com essa criança (...) uma educação continuada também já resolveria, parcialmente, $o$ problema..." (VIII)}

A partir de um programa que conheça, avalie periodicamente e respeite os profissionais, será possível identificar habilidades e potencialidades de cada indivíduo e, talvez, com isso, alcançar um nível de excelência na assistência prestada aos pacientes. Algumas afirmações dos entrevistados pontuam sobre essa questão:
“(...) acho que o profissional aqui deveria ter a opção com quem ele quer trabalhar. Se você quer trabalhar com criança, então vai trabalhar com criança. Você não quer, então não trabalhe, porque você não vai trabalhar bem, e a criança sente isso. O adulto também sente..." (VI)

“(...) uma educação continuada (...) vai melhorar a questão prática do teu dia-a-dia, da tua prática; desde conversar com os pais, com a criança, com qualquer paciente. Você iria ter mais vivência, pra poder atender esses pacientes. Melhoraria a qualidade do serviço..." (VIII)

\section{O envolvimento emocional, a espiritualidade, a condição de maternidade e família como influências presentes.}

O discurso dos entrevistados remete à necessidade de envolvimento, por tratar-se de crianças, o que faz com que os profissionais andem no limiar entre envolvimento profissional e pessoal:

“(...) você tem que aceitar aquela criança como parte do seu trabalho e que o seu cuidado é importante pra ela...” (II)

“(...) eu sempre penso: essa criança podia ser minha, essa criança podia ser um primo, um sobrinho. Sempre me coloco no lugar da família da criança..." (IV)

O cuidado está, muitas vezes, vinculado ao lado afetivo. A expressão dos sentimentos, a compreensão e preocupação com o outro, particularmente no caso de crianças, acabam por criar laços. As entrevistas a seguir mostram as manifestações de afetividade e envolvimento emocional que ocorrem no atendimento:

“(...) uma criança lembrar de você, querer que você cuide dela, tudo isso é muito gratificante..." $(V)$

“(...) eu fico feliz quando alguém sai daqui bem e você vê as crianças grandes, crescendo, saber que você fez parte do processo de recuperação, que você colaborou com aquela criança; eu fico satisfeito de saber que participei, contribuí de alguma forma..." (VIII)

Contudo, esse envolvimento não representa ao profissional apenas uma atitude solidária e humanizada; em muitos momentos, gera sofrimento psíquico e um sentimento de renúncia de seus sentimentos pelo da criança:

“(...) tem alguns pacientes que eu me apego demais, mesmo não querendo, e eu acabo sofrendo muito...” (VI)

“(...) eu choro, muitas vezes. Eu sofro junto...” (VII)

“(...) eu acho que o maior objetivo é fazer eles ficarem sem dor, ficarem bem..." (VI)

Outros profissionais, para evitar esse sofrimento, criam barreiras de defesa, tentam não se envolver, ou dizem "deletar", esquecer coisas acontecidas no ambiente de trabalho para não sofrer. Alguns fragmentos dos discursos atestam isso:

“(...) eu tento não me envolver muito. Eu não me envolvo. Eu faço assim minha parte. Eu trato a criança com carinho e tudo, mas tento não me envolver demais, eu acho que até pra não sofrer...” (IV)

“(...) eu esqueço porque eu tenho esse..., eu acabo bloqueando as pessoas. Acho que isso é uma forma de proteção minha..." (VII) 
Embora alguns profissionais recorram a técnicas de defesa frente ao sofrimento imposto pelo serviço, a busca pela cura, a decepção frente à falta de êxito nessa busca que às vezes acontece, acabam por deprimir, especialmente nas pessoas mais próximas à criança, como pode ser percebido na fala dos entrevistados:

“(...) quando acontece isso, parece que fica um pedacinho, parece que um pedacinho da gente morre junto... " (VI)

“(...) ela morreu com dor, morreu segurando minha mão e pedindo pra tirar a dor dela (...) E, então, quando tu não consegue, quando eu não consigo, realmente isso me afeta bastante..." (VI)

O cuidado realizado por esses profissionais, contudo, supera o sofrimento, mesmo que, às vezes para isso, os profissionais relatem apegarem-se a crenças religiosas:

“(...) uma coisa, primeira coisa, eu acredito em Deus (...), eu faço minhas orações, eu sempre peço por esses pacientes que estão aqui...” (VI)

“(...) acho que é uma coisa de Deus. Essa fé, acreditar em Deus, ver que Deus tem um papel pra gente aqui dentro... eu acho que isso fortalece muito a gente..." (VII)

A fé, para a equipe que presta assistência a crianças gravemente doentes, pode ser a força que a impulsiona e que garante energia para prosseguir em sua tarefa de conciliar competência técnica à humanização no atendimento. Alguns entrevistados evidenciaram tal constatação:

“(...) dependendo do caso, às vezes eu acordo de noite pensando. Quando isso acontece, geralmente eu faço uma oração, pra eu conseguir também ficar bem...” (VI)

“(...) eu gosto de trabalhar no transplante. Eu me sinto bem aqui. Fico triste, às vezes (...) eu acho que Deus colocou uma vocação pra gente. (...) isso me dá muita força, dá coragem de voltar ao trabalho, de começar, de lutar..." (VII)

Ações simples, como conversar, realizar escuta ativa, mostrarse receptivo frente às necessidade de cuidado com a criança podem diminuir a ansiedade e o medo de crianças e acompanhantes. ${ }^{14}$ Algumas dessas afirmações aparecem de forma marcante nas entrevistas:

“(...) mas tem a questão emocional e, principalmente, o envolvimento da família. Às vezes, a família é necessária pra criança, importante, só que dificulta pra gente...” (I)

“(...) tem pais que ajudam, mas tem pais que atrapalham, no sentido de muita ansiedade, às vezes até interferindo no nosso serviço...” (IV)

Outra questão abordada é a relação com o sofrimento dos familiares, em particular o da mãe. Muitas vezes, a despeito de todo seu empenho, a mãe presencia o sofrimento de seu filho e, evidentemente, sofre junto sem ter muito que fazer. A mãe enfrenta tudo para cumprir o que define como sendo seu dever de mãe. O fato de estar acompanhando o filho doente, hospitalizado, desperta uma vastidão de eventos que promovem medo, angústia e insegurança. Esses sentimentos são reais e constantes e aumentam proporcionalmente na medida em que aumenta o tempo de internação, a observação e constatação do que acontece com outras crianças, especialmente o agravamento das condições de saúde ou óbito.

\section{DISCUSSÕES}

A equipe de enfermagem precisa estar preparada para receber crianças que precisam ser submetidas a transplante de medula óssea e suas famílias, com segurança, habilidades técnicas e preocupação com a humanização da assistência hospitalar. O desafio para os profissionais está justamente no novo, no que é diferente, na adaptação que se faz necessária num ambiente que não o próprio.

A comunicação é fator deliberante na união de esforços entre crianças, pais e equipe, pois ela pode amenizar conflitos gerados pela hospitalização, que muitas vezes se manifestam em dificuldade de desenvolver tarefas, atitudes ou atividades naturais e rotineiras para os pais, que são executadas facilmente em casa, e que dentro do hospital, parecem extremamente difíceis ou até mesmo impossíveis.

Muitos outros desafios, além da comunicação, apresentam-se todos os dias aos profissionais da área hospitalar, especialmente àqueles que trabalham com crianças; o enfermeiro, atuando no cuidado, vivencia diferentes relações com o indivíduo, promovendo alívio da dor, conforto até mesmo pela palavra, restabelecimento da saúde e doação de amor. ${ }^{8}$

Em especial quando o cuidado é direcionado a crianças, é preciso pensar nela, em sua doença, seu tratamento específico, nas possíveis complicações, na assistência humanizada, bem como em envolver a família na assistência, criando condições para que participe, respeitando seus limites emocionais, mas acreditando nas habilidades que tem em prestar cuidados ao filho durante todo o período de hospitalização da criança. ${ }^{9}$

Outro aspecto que precisa ser considerado é a necessidade de educação permanente no Serviço; partindo-se do princípio de que o objetivo dessa educação é promover o aprimoramento dos profissionais de enfermagem através de ações educacionais planejadas, orientações, treinamento e avaliação periódicos, esse serviço deveria funcionar como ponto de partida para um auxílio constante e eficaz aos profissionais.

Para que os profissionais possam prestar cuidado adequado às crianças hospitalizadas sem descuidar do apoio às famílias, é preciso que estejam bem, não só do ponto de vista profissional, mas também emocional. Vários estudos têm sido realizados tentando diminuir o estresse diário enfrentado pela enfermagem, direcionando alternativas de cuidado do outro em harmonia com o cuidado de si mesmo. A integridade física e emocional de quem cuida é uma etapa fundamental para o exercício do cuidar como ação terapêutica da enfermagem. ${ }^{10}$

Em algumas unidades do hospital, especialmente as que prestam assistência a crianças além do conhecimento técnico, há necessidade de maior domínio teórico e prático e também envolvimento emocional, a fim de criar um clima de proximidade e tornar o relacionamento mais fácil. Trata-se de criar um vínculo de confiança e acolhimento, que represente uma terapêutica eficiente a ser ofertada pela equipe de saúde, como é o caso do serviço de transplante de medula óssea, seja por suas especificidades seja pelo envolvimento emocional e vínculos propiciados pela vivência nesse ambiente.

No cuidado à criança, a sensibilidade atua como elemento indispensável, principalmente porque as crianças, por suas características peculiares, tornam difícil o não envolvimento na prestação do cuidado. Sendo, pois, evidenciado o envolvimento emocional no cuidar, reflete-se sobre o sofrimento como intensificador desse envolvimento. ${ }^{11}$ 
É incontestável que viver constantemente com a dor, tristeza, sofrimento dos pacientes é muito desgastante, e a maneira encontrada pelos profissionais para diminuir essa fragilidade emocional é criar uma defesa, bloqueando ou esquecendo suas vivências de sofrimento no seu ambiente de trabalho. Entretanto, existem situações mais complicadas fortemente presentes, pouco discutidas e difíceis de esquecer, sendo a mais marcante a morte. Esse momento difícil de ser vivido e superado pela equipe que está junto em todo o processo de doença e tentativa de cura sem êxito deprime e faz com que, especialmente pessoas mais próximas sofram demasiadamente.

Entretanto, ainda que pareça desalentador, cuidar de crianças pode ser extremamente gratificante quando se pensa no "algo a mais" que isso representa. Muitas vezes, os profissionais procuram encontrar na fé a força para trabalhar e enfrentar os embates que a profissão lhes proporciona. Vivenciar o sofrimento, a dor e angústia das crianças também lhes causa angústia e, por isso, necessitam apoiar-se em algo ou alguém e buscar energias para suas atividades.

Para muitas pessoas, a religião e as crenças pessoais e espirituais são fonte de conforto, bem-estar, segurança, inclusão, ideal e força. ${ }^{12}$ Além disso, fatores como o cuidado emocional consigo mesmo e reconhecimento de seu próprio universo subjetivo existencial e espiritual dão significado à própria existência do cuidador, sem deixar de se sensibilizar com os valores e sentimentos do outro. ${ }^{13}$

A presença do familiar é importante para a criança, para sua recuperação, superação e estabilidade emocional, pois é no familiar significativo que ela irá se apoiar; contudo, esses familiares podem desenvolver sentimento de culpa nesse processo. ${ }^{14}$ Assim, a enfermagem precisa estar preparada para uma atuação conjunta, respeitando os conhecimentos, sentimentos e comportamentos da família e/ou acompanhante,,${ }^{15}$ buscando principalmente a humanização. ${ }^{14}$

\section{CONCLUSÕES}

Os longos períodos de internação, a sofisticada tecnologia, as características próprias da clientela infantil com sua maneira de expressar dor e o sofrimento, de enfrentar a necessidade de exames e procedimentos por vezes dolorosos e desagradáveis, as rotinas e ruídos próprios do hospital, a adaptação ao desconhecido8 podem fragilizar os profissionais que, embora solidários e afetuosos, nem sempre estão preparados, adaptados ou dispostos a enfrentar essas situações que se apresentam à rotina de uma unidade de cuidados de alta complexidade. ${ }^{16}$

Este estudo se faz importante por tentar compreender as repercussões do serviço de transplante de medula óssea nos próprios profissionais de enfermagem, o que possibilita subsídio emocional para sua atuação nessa área. Ressalta que compreender a experiência do paciente, considerando seus aspectos positivos e negativos, sabendo que a doença é ao mesmo tempo privação e reformulação especialmente quando essa doença é grave e pode levar à incapacidade ou diminuição no ritmo de vida habitual, com tratamentos prolongados e capazes de deixar seqüelas permanentes, é parte do trabalho da enfermagem. Cabe a esse profissional entender que o cuidado vai além da patologia, incluindo as relações com a criança e a família, ${ }^{16}$ muito embora essa relação possa ser uma questão emocional difícil para o profissional.

Essa realidade pode gerar ansiedade nos profissionais de enfermagem, o que, algumas vezes, foi relatada como reflexo da falta de preparo técnico e do pouco embasamento científico também mostra-se na dificuldade de comunicação com as crianças, em se fazer entender e também em entender suas necessidades, bem como em conviver com os pais. Reconhecer a importância e necessidade da presença dos pais não é problema; o fator de dificuldade reside no fato de não ter havido preparo prévio para essa situação.

Finalmente, apesar das dificuldades, angústias, sofrimento, imposição, falta de preparo, conhecimento, treinamento e de um ambiente apropriado à assistência de crianças, os profissionais do Serviço de Transplante de Medula Óssea têm se esforçado no intuito de proporcionar um atendimento de alta qualidade às crianças submetidas a transplante de células tronco hematopoéticas.

Por representar um ambiente com características peculiares, principalmente quando se trata de crianças, acredita-se que seja importante que novas pesquisas sejam realizadas juntamente aos serviços de transplante de medula óssea, a fim de subsidiar o profissional que atua nessa área tanto cientifica como emocional e psicologicamente.

\section{ABSTRACT}

Highly complex procedures as bone marrow transplantation cause uncertainness, fear, and affliction feelings, mainly when related to Pediatrics, which is a worrying and enchanted theme. Purpose: to understand how nursing professionals perceive themselves upon the attendance of children submitted to bone marrow transplantation. Method: speech analysis by phenomenological approach. Results: two main themes related to the nursing care to children submitted to hematopoietic stem cells transplantation: demand to face constant challenges and difficulties reflected on the need for continuing education and the emotional involvement, spirituality, motherhood and family as present influences. Conclusion: professional lack of preparation in dealing with Pediatrics peculiarities involved in transplant process and the effort of professionals in such kind of service.

Keywords: Hospitalized Child; Bone Marrow Transplantation; Nursing; Workload. 


\section{REFERÊNCIAS}

1. Wayhs RJ, Souza AIJ. Estar no hospital: a expressão de crianças com diagnóstico de câncer. Cogitare Enferm. 2002;7(2):35-43.

2. Araújo A, Faveretto J, Sperfild M. A percepção das crianças e de seus familiares sobre a hospitalização em um conjunto pediátrico. Faculdade Assis Gurgacz [Article online] 2008 [cited 2009 feb 13]; 5-33. Available from: http://www.fag.edu.br/ tcc/2008/Enfermagem/a_percepcao_das_criancas_e_de_seus_familiares_sobre_a_ hospitalizacao_em_um_conjunto_pediatrico.pdf

3. Collet N, Oliveira BRG. Enfermagem pediátrica. Goiânia: AB Editora; 2002.

4. Ortega ETT, Veran MP, Kojo TK, Lima DH, Neves MI. Compêndio de enfermagem em transplante de células tronco hematopoéticas: Rotinas e procedimentos em cuidados essenciais e em complicações. Curitiba: Editora Maio; 2004.

5. Costenaro RGS, Lacerda MR. Quem cuida de quem cuida? Quem cuida do cuidador? Santa Maria: Centro Universitário Franciscano; 2002.

6. Brasil. Conselho Nacional de Saúde. Resolução nº 196, de 10 de outubro de 1996 - Resolve aprovar diretrizes e normas regulamentadoras de pesquisas envolvendo seres humanos. Diário Oficial da União. Brasília [online] 1996 [Cited 2008 oct 25]. Available from: http://conselho.saude.gov.br/resolucoes/1996/Reso196.doc

7. Martins J, Bicudo MAVP. Estudos sobre existencialismo, fenomenologia e educação. São Paulo: Editora Moraes; 1983.

8. Ciuffo L, Rodrigues B, Cunha J. The nurse in sexual abuse child suspicion attention: a phenomenology approach. Online Braz J Nursing [serial online] 2009 [,Cited 2009 jan. 02]; 8(3). Available from: http://www.objnursing.uff.br/ index.php/nursing/article/view/2665
9. Reksua VM, Silva AA, D'oro MP. O cuidado humanizado no serviço de transplante de medula óssea. In: Ortega ETT, Veran MP, Kojo TK, Lima DH, Neves MI. Compêndio de enfermagem em transplante de células tronco hematopoéticas: Rotinas e procedimentos em cuidados essenciais e em complicações. Curitiba: Editora Maio; 2004. p. 79-87.

10. Hoga LAK. Cuidando do cuidador. In: Congresso Brasileiro de Enfermagem, 50, 1998, Salvador; Anais: 278-85.

11. Costa JC, Lima RAG. Luto da equipe: revelações dos profissionais de enfermagem sobre o cuidado à criança/ adolescente no processo da morte e morrer. Rev. Latinoam. Enferm.. 2005;13(2):151-7.

12. Flecka MPA, Borgesb ZN, Bolognesia G, Rocha NS. Desenvolvimento do WHOQOL, módulo espiritualidade, religiosidade e crenças pessoais. Rev. Saúde Pública. 2003; 37(4):446-55.

13. Neves EP. Cuidando e confortando o cuidador profissional: um referencial fundamentado em Jean Watson. In: Congresso Brasileiro de Enfermagem, 53, 2001, Curitiba, Anais: 299-307.

14. Zambrotti GPO, Cruz I. Literature review on risk for impaired parenting - OBJN Club Journal. Online Braz J Nursing [serial online] 2004 [,Cited 2008 may 20]; 3(1). Available from: www.uff.br/nepae/objn301zambrotti.htm

15. Souza AIJ, Ribeiro EM, Eckert ER. Dialogando com a equipe de enfermagem sobre as necessidades educativas dos acompanhantes de crianças internadas: construindo caminhos para o cuidado à família. Texto Contexto Enferm. 2003;12(3):280-8.

16. Silva GM, Teles SS, Valle ERM. Estudo sobre as publicações brasileiras relacionadas a aspectos psicossociais do câncer infantil -período de 1998 a 2004. Revista Brasileira de Cancerologia. 2005;51(3):253-61. 